\title{
The Propagation of Horizontally Polarized Shear Wave in the Hollow Cylinder
}

\author{
Yu. V. Myshkin, O. V. Murav’eva, Yu. O. Sannikova, T. S. Chukhlanceva \\ Department of Instruments and Techniques for Measurement, Testing, Diagnostics, \\ Kalashnikov Izhevsk State Technical University, \\ Izhevsk, Russian Federation \\ E-mail: mubm@yandex.ru
}

Received: July 06, 2018

\begin{abstract}
The paper presents studies of the velocity of propagation of a horizontally polarized shear wave (SH wave) in an aluminum hollow cylinder. The results of simulation of SH wave propagation using the finite element method are presented. Approbation was carried out on an aluminum cylinder using piezoelectric transducers with a dry point contact at a frequency of $105 \mathrm{kHz}$. Dependences of the $\mathrm{SH}$ wave velocity on the direction of propagation in a hollow cylinder are obtained.
\end{abstract}

Keywords: SH wave, hollow cylinder, wave velocity, finite element method, dry point contact, guided wave testing.

\section{INTRODUCTION}

The modern acoustic guided wave method in nondestructive testing is based on the use of longitudinal, torsional or flexural waves, as well as symmetric and antisymmetric modes of Lamb waves [1-3]. In studying the processes of propagation of these types of waves in plates and hollow cylinders, in most cases it is assumed that the properties of the material in which the wave propagates are isotropic. In the presence of anisotropy, as a rule, the pattern of velocity distribution along the directions changes [4-6]. Changes in the velocity of wave propagation are also caused by inhomogeneities in the cross section, structural features of the control object, and various types of defects $[3,5-6]$. When studying the change wave velocity under the influence of these factors, it is necessary to take into account the qualitative state of the testing object, the presence in it of stressed-deformed sections, the design features of the transducers used, the parameters of the hardware, the size and position of the defects, and etc. $[2,5-8]$

It is known from literature sources [3,9-17] that when testing pipelines in circumferential and axial directions, SH waves (or tH waves) are used. The advantage of using this type of wave is that the fundamental mode SH0 does not have dispersion, is more sensitive to defects, and has a relatively smaller attenuation [3, 18-23]. To increase the sensitivity of the guided wave method, focusing methods using phased arrays [24-30] are practiced. The most common are the synthetic aperture focusing technique (SAFT) [30-36], the total focusing method

(C) Myshkin Yu. V., Murav’eva O. V., Sannikova Yu. O., Chukhlanceva T. S., 2018 
(TFM) [25, 37-39], the common source method (CSM) [32, 40]. When using any of the methods for calculating the coordinates of the focus point, the wave propagation velocity is used, while it is assumed that it does not change depending on the direction. In the presence of anisotropy of the material properties of the pipeline, the velocity change from the direction is taken into account. Nevertheless, even in an isotropic material, in the presence of bends and deformations of the testing object, the wave velocity can have significant distinctions in different directions.

This paper presents numerical and experimental studies of the propagation velocity of the SH0 mode of a shear wave in a hollow cylindrical aluminum isotropic testing object with a diameter of $300 \mathrm{~mm}$ at a frequency of $105 \mathrm{kHz}$.

\section{GENERAL THEORY}

All types of waves can exist in solids: volumetric (longitudinal and transverse waves), surface and subsurface (Rayleigh and head waves), Lamb waves in layered media, and Pochhammer waves in rods. Longitudinal oscillations are associated with the elasticity of the volume of the medium and can propagate in solid, liquid, and gaseous media. Transverse (shear) vibrations are associated with the elasticity of the shape and can only propagate in a solid medium that is capable of resisting shear deformation. Due to the polarization process, i.e. the relationship of the direction of propagation and the direction of particle oscillation, for example, transverse waves can be horizontally and vertically polarized. A horizontally polarized transverse (shear) wave is also called a $\mathrm{tH}$-wave, in which the particles of the medium oscillate perpendicularly to the plane of incidence. Such wave represents a pure shift [28].

Guided waves (Pochhammer waves, guided longitudinal, flexural and torsional waves, Lamb waves) exist in testing objects, which are represented layered media (bars, pipes, tubes, rods, plates, etc.). Guided waves, in turn, are divided into two types: longitudinal (symmetrical) and flexural (antisymmetric) waves. In longitudinal guided waves, the motion occurs symmetrically with respect to the axial direction of testing object and the axial (longitudinal) displacement component predominates. In flexural guided waves in the axial direction, flexure occurs and the transverse component of displacements predominates. In addition to symmetrical and antisymmetrical waves, a torsional wave can propagate in extended cylindrical objects, in which there is only one azimuth displacement component. The motion of the wave is symmetrical with respect to the axial direction and represents the rotation of the cross section of the cylindrical object with respect to this axis [28].

Waves propagating along the surface of the material are called Rayleigh or surface waves. These waves have elliptical motion of particles [28].

The types of waves are shown in Table 1. As an example, in Figure 1 shows the dispersion curves for an aluminum plate with a thickness of $5.675 \mathrm{~mm}$ and a hollow cylinder with an outer diameter of $300 \mathrm{~mm}$, which are studied in the work.

In studies of the propagation of a horizontally polarized shear wave, the frequency was $105 \mathrm{kHz}$. From the above dispersion curves it follows that, at a given frequency, the fundamental symmetric and antisymmetric modes of the Lamb wave and the horizontally polarized shear wave can exist in the testing object when considering it in the form of a curved plate. When considering the testing object in the form of a hollow cylinder, taking into account the wave propagation along the waveguide (in axial direction of the cylinder), there may exist in it modes of the lowest order of the longitudinal and flexural waves and the fundamental mode of the torsional wave. Since the direction of wave propagation is taken into account in this work, the velocities of the symmetric mode $5329 \mathrm{~m} / \mathrm{s}$, the antisymmetric mode $3012 \mathrm{~m} / \mathrm{s}$ and the horizontally polarized shear wave of $3162 \mathrm{~m} / \mathrm{s}$ are used as theoretical data (Figure 1a). 
Myshkin Yu. V., Murav’eva O. V., Sannikova Yu. O., Chukhlanceva T. S.

"The propagation of horizontally polarized shear wave in the hollow cylinder"

Table 1. Wave type designation and description

\begin{tabular}{c|c}
\hline Wave & Description \\
\hline $\mathrm{L}(0, \mathrm{~m})$ & Axisymmetric mode of guided longitudinal wave, $\mathrm{m}$ - mode number \\
$\mathrm{T}(0, \mathrm{~m})$ & Axisymmetric mode of guided torsional wave, $\mathrm{m}$ - mode number \\
$\mathrm{F}(\mathrm{n}, \mathrm{m})$ & Non-axisymmetric mode of guided flexural wave, $\mathrm{n}$ - circumferential order, $\mathrm{m}$ - mode \\
$\mathrm{Am}$ & number \\
$\mathrm{Sm}$ & Antisymmetrical mode of Lamb wave, $\mathrm{m}$ - mode order number \\
$\mathrm{SHm}$ & Symmetrical mode of Lamb wave, $\mathrm{m}-$ mode order number \\
$\mathrm{R}$ & Horizontally polarized shear wave, $\mathrm{m}-$ mode order number \\
\hline
\end{tabular}
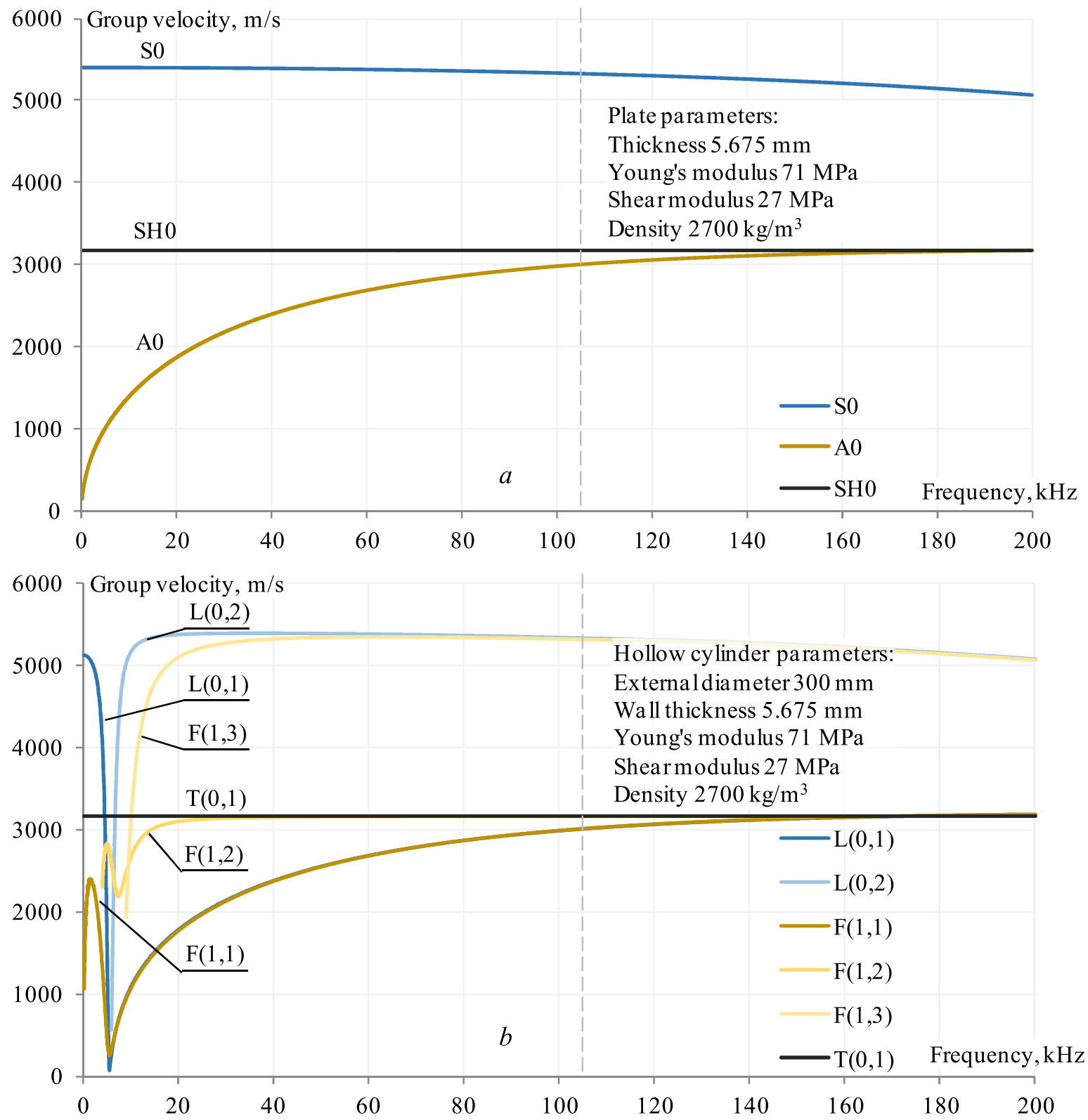

Figure 1. Dispersion curves of group velocities in an aluminum plate $(a)$ and an aluminum hollow cylinder $(b)$ : S - symmetrical mode of Lamb wave, A - antisymmetrical mode of Lamb wave, SH - horizontally polarized shear wave, $\mathrm{L}$ - longitudinal wave, $\mathrm{F}$ - flexural wave, $\mathrm{T}$ - torsional wave (designations are presented in Table 1) 


\section{FINITE ELEMENT PREDICTION}

Numerical calculation was carried out using the finite element method, implemented in COMSOL Multiphysics. The model (Figure 2) included a cylindrical aluminum object with length of $1.2 \mathrm{~m}$, with an internal cavity $288.65 \mathrm{~mm}$ in diameter, and a wall thickness of $5.675 \mathrm{~mm}$ (Figure $2 a$ ). The discretization step for the finite element grid (mesh) was selected based on the condition: at least five finite elements per wavelength. Thus, the grid step was no more than $5.81 \mathrm{~mm}$, and the total number of finite elements is 300963 (Figure $2 b$ ).

On the outer cylindrical surface, in the middle of the object, the only (in addition to the default boundary conditions: Linear elastic material, Free, Initial values) boundary condition Point Load was set in the form of a tangential azimuth force action (Figure 2a). The form of the force action is shown in Figure 3, has a fundamental frequency in the pulse spectrum of $105 \mathrm{kHz}$ and is described by the formula:

$$
U(t)=U_{0} \cdot e^{-\beta t^{2}} \cdot(\omega \cdot \cos (\omega t)-2 \beta \cdot \sin (\omega t)),
$$

where $U_{0}$ is the amplitude, $\beta$ is the attenuation coefficient, $t$ is the time, $\omega=2 \pi f$ is the cyclic (circular) frequency.

Table 2. Material properties

\begin{tabular}{c|c|c}
\hline Parameter & Value & Dimension \\
\hline Young's modulus, $E$ & 71 & $\mathrm{GPa}$ \\
Shear modulus, $G$ & 26.7 & $\mathrm{GPa}$ \\
Poisson's ratio, $\eta$ & 0.33 & - \\
Shear wave velocity, $C$ & 3145 & $\mathrm{~m} / \mathrm{s}$ \\
Density, $\rho$ & 2700 & $\mathrm{~kg} / \mathrm{m}^{3}$ \\
\hline
\end{tabular}
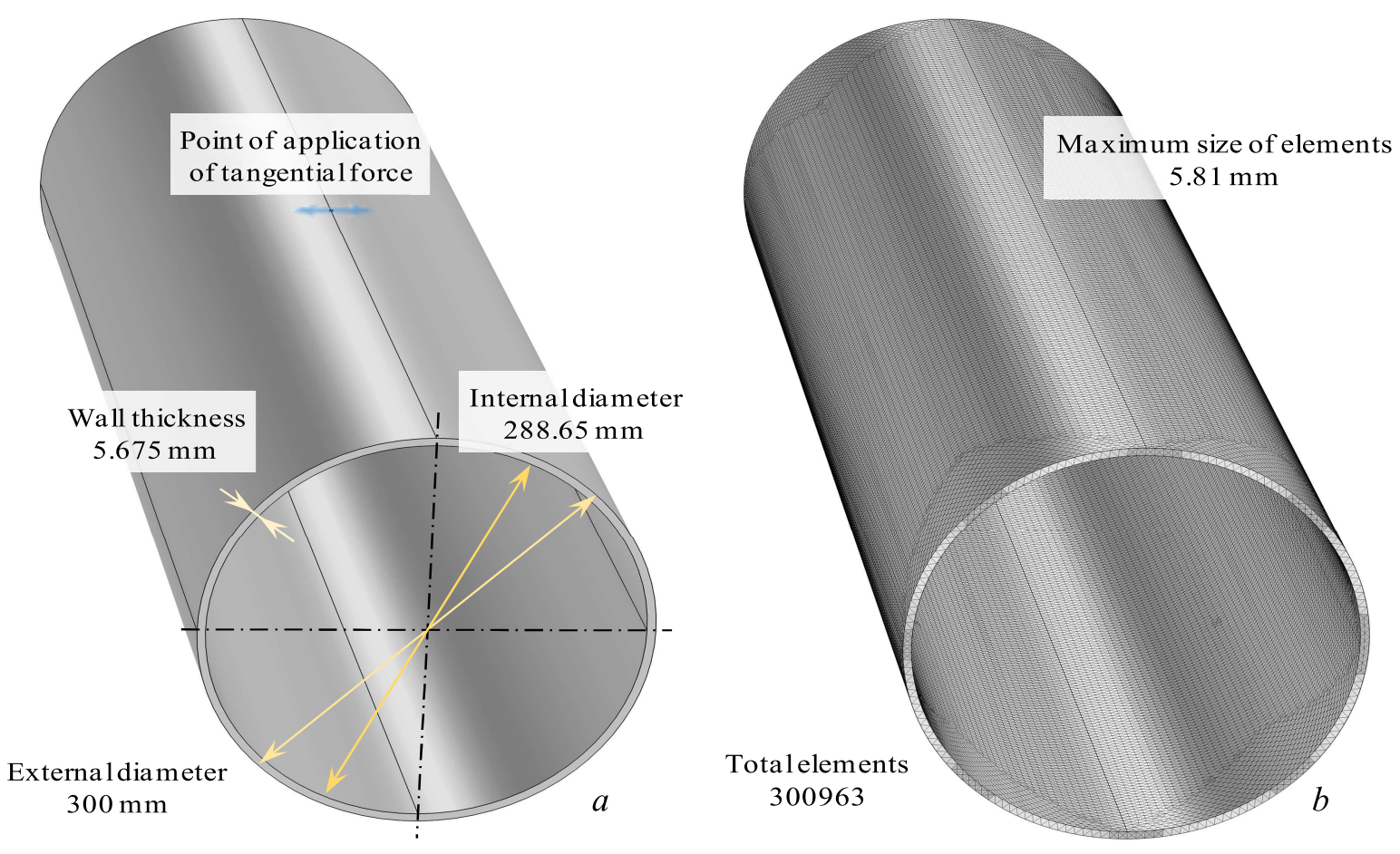

Figure 2. 3D model of the pipe $(a)$ and finite element mesh $(b)$ : pipe length is $1.2 \mathrm{~m}$, point of application of tangential force is located at a distance of $0.6 \mathrm{~m}$ from the pipe end 
Myshkin Yu. V., Murav’eva O. V., Sannikova Yu. O., Chukhlanceva T. S.

"The propagation of horizontally polarized shear wave in the hollow cylinder"

Table 3. Input parameters

\begin{tabular}{l|c|c}
\hline \multicolumn{1}{c|}{ Parameter } & Value & Dimension \\
\hline External diameter of cylinder, $R_{\text {ext }}$ & 150 & $\mathrm{~mm}$ \\
Internal diameter of cylinder, $R_{\text {int }}$ & 144.325 & $\mathrm{~mm}$ \\
Cylinder length, $L$ & 1.2 & $\mathrm{~m}$ \\
Frequency, $f$ & 105 & $\mathrm{kHz}$ \\
Period, $T$ & 9.524 & $\mu \mathrm{s}$ \\
\hline
\end{tabular}

With such force action, a SH wave directed along the cylinder, a symmetric Lamb wave mode directed in circumferential direction, and an antisymmetric mode propagating in all directions were formed in the hollow cylinder. At the initial moment of time, the shape of the elastic displacements pulse has a similar shape (Figure 3) and at an amplitude of the force action of $6.6 \mathrm{~N}$ has a displacement amplitude of $50 \mathrm{pm}$.

As an example, in Figure 4 shows the distribution of elastic displacements at time $40 \mu \mathrm{s}$ and $100 \mu \mathrm{s}$. A symmetric S0, an antisymmetric A0 of the modes of the Lamb wave, and a horizontally polarized shear wave $\mathrm{SH} 0$ are observed.

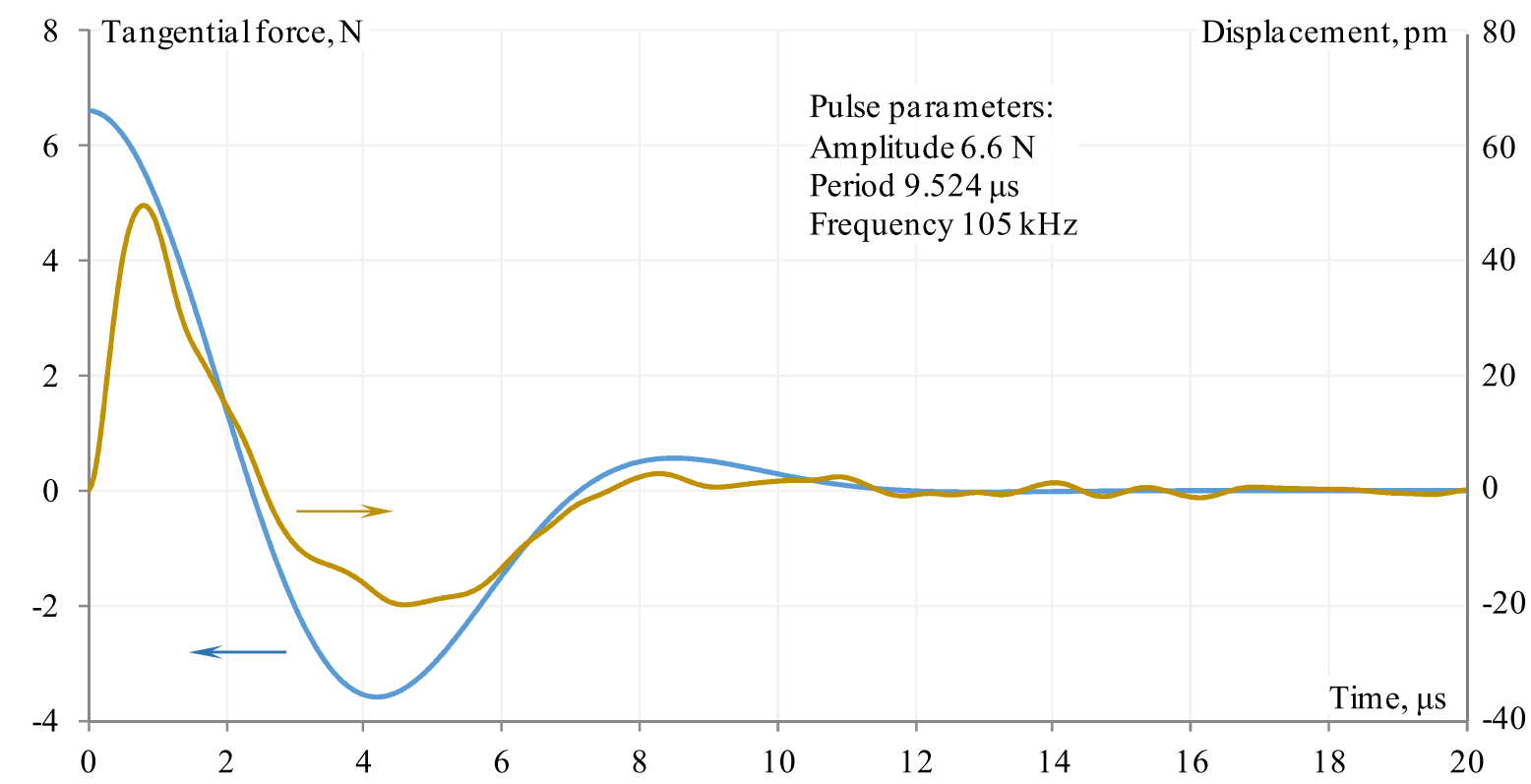

Figure 3. Pulse of the tangential force action (calculated by the Formula 1) and the shape of the elastic displacements pulse (calculated in the program): arrows indicate the correspondence of the graphs to the axes

To estimate the propagation velocity of the $\mathrm{SH}$ wave, formulas for constructing registration points equidistant from the point of application of the tangential force action at a distance of $300 \mathrm{~mm}$ are used which describe the construction of a circle in a cylindrical coordinate system:

$$
\begin{gathered}
x=R \cdot \sin \left(\frac{D}{R} \cdot \sin (\alpha)\right), \\
y=h_{0}+R \cdot \cos (\alpha), \\
z=R \cdot \cos \left(\frac{D}{R} \cdot \sin (\alpha)\right),
\end{gathered}
$$


where $R$ is the outer radius of the hollow cylinder, $D$ is the outer diameter of the hollow cylinder, $\alpha$ is the angle of propagation direction of the wave (varies from $-\pi / 2$ to $3 \pi / 2$ in steps of $\pi / 180), h_{0}$ is the coordinate along the $y$ axis, where applied the tangential force (the height of the cylinder is directed along the $y$ axis).
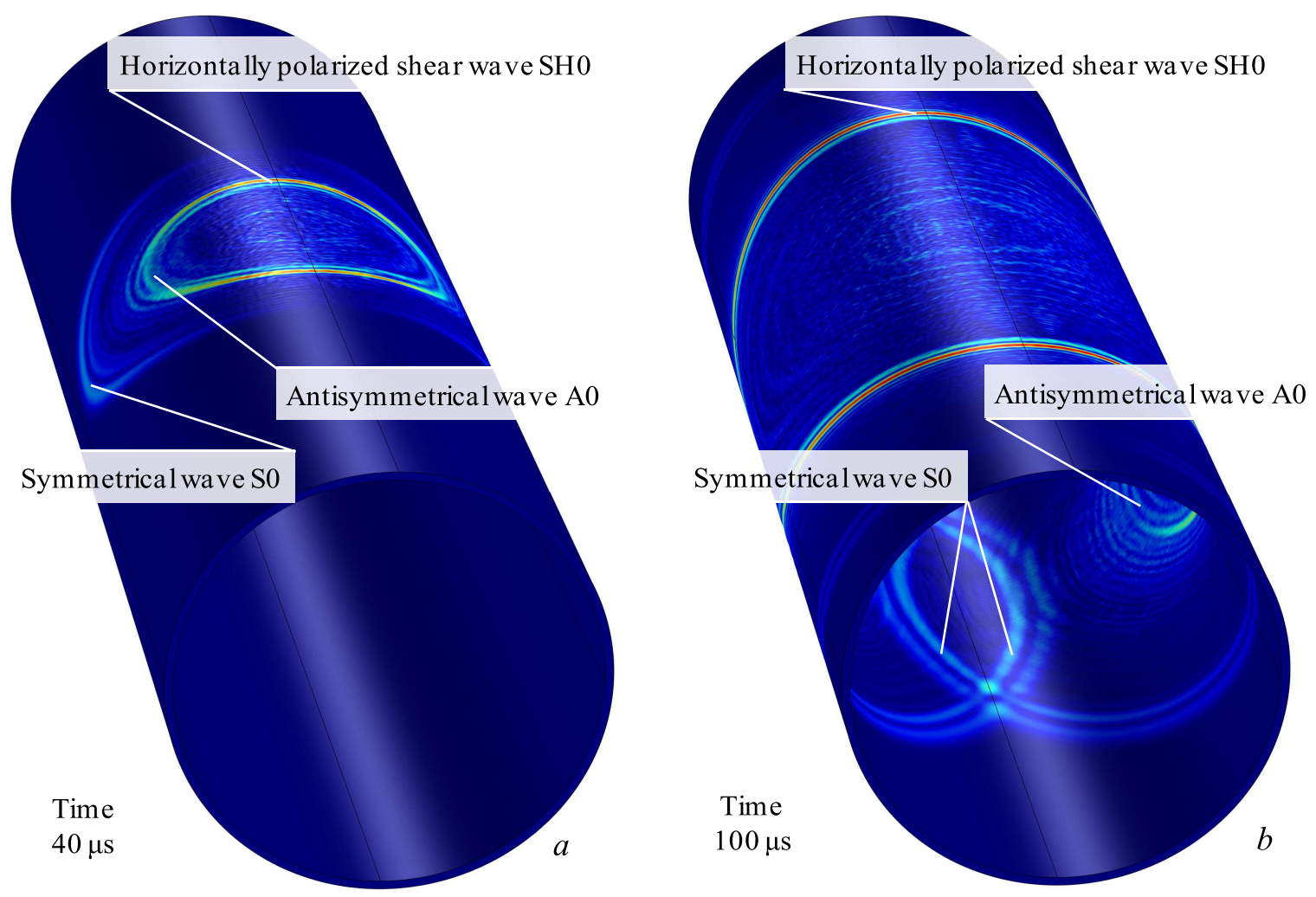

Figure 4. Distribution of displacements at time $t=40 \mu \mathrm{s}(a)$ and $t=100 \mu \mathrm{s}(b)$ : rainbow graduation is used, the dark blue color corresponds to zero displacements, the dark red corresponds to the maximum displacements (approximately $50 \mathrm{pm}$ )

Using these formulas, the amplitude of the displacements at the points on the surface of the hollow cylinder was estimated (Figure 5) and the signals were plotted for the displacement components (Figure 6). As the analyzed one, the azimuth component is chosen whose displacement corresponds to the displacements in the SH wave directed along the axis of the hollow cylinder.

In the presented signals (Figure 6), displacements corresponding to the symmetric S0 and antisymmetric A0 modes of the Lamb wave and the horizontally polarized shear wave SH0 are observed. The symmetrical mode in the frequency range up to 10 to $500 \mathrm{kHz}$ has a high dispersion, its velocity varies from $5200 \mathrm{~m} / \mathrm{s}$ at a frequency of $10 \mathrm{kHz}$ to $1760 \mathrm{~m} / \mathrm{s}$ at a frequency of $440 \mathrm{kHz}$, so on the signal accepted in the axial direction, low-frequency LF and high-frequency HF symmetric mode of the Lamb wave are observed. There is also a symmetric mode of the Lamb wave of the second order S2 at a frequency of $670 \mathrm{kHz}$, whose velocity is $4730 \mathrm{~m} / \mathrm{s}$. In the circumferential direction of the cylinder, the symmetrical mode is registered in the forward direction FD and in the reverse direction RD. The distance traveled by the wave corresponds to $300 \mathrm{~mm}$ and $642.5 \mathrm{~mm}$. 


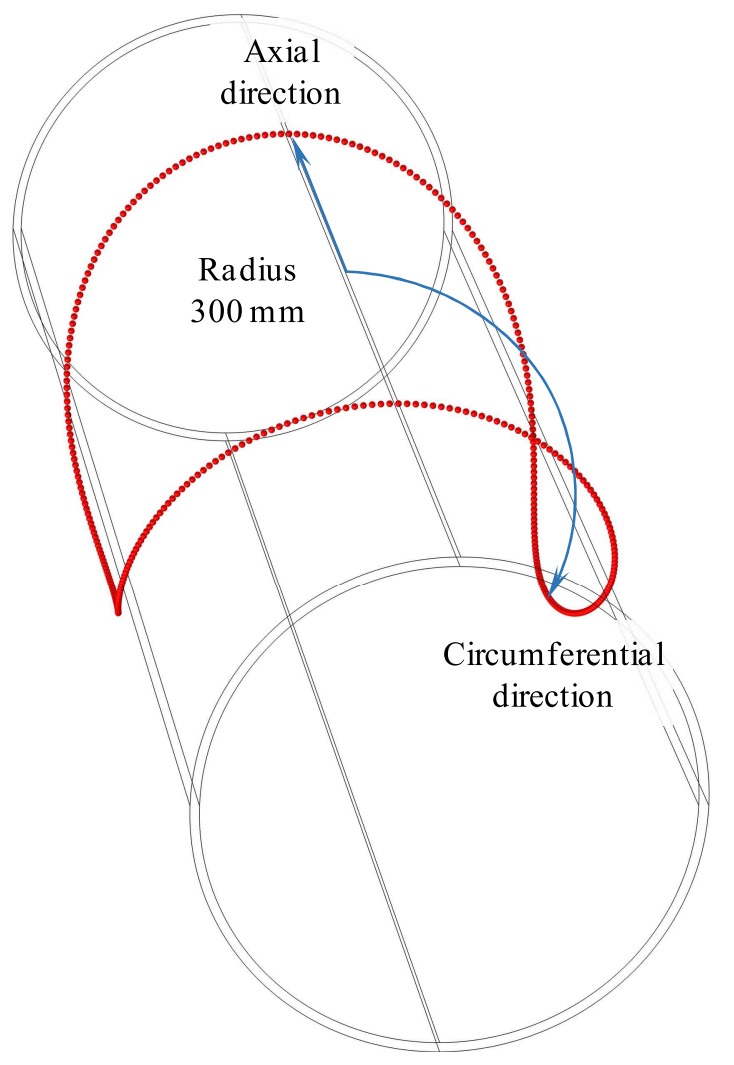

Figure 5. Points on the outer surface of a hollow cylinder (calculated by Formulas 2) in which the amplitude of elastic displacements was registered
The main disadvantage in the study is the presence of an antisymmetric mode, which propagates at a velocity comparable to the velocity of a horizontally polarized shear wave. The pulse shape of the antisymmetric mode contains a whole spectrum of frequencies and represents a pulse with a highfrequency component that smoothly converts to a low-frequency component having a lower velocity. To avoid the influence of the antisymmetric mode on the measurement result, a band-pass filter of high order with cut-off frequencies of 90 and $120 \mathrm{kHz}$ was used to analyze the propagation velocity of a horizontally polarized shear wave.

The investigated horizontally polarized shear wave had the expected maximum amplitude of displacements in the axial direction, which gradually decreased with the change in the registration coordinates of the signal. The shape of the pulse had a similar form with the shape of the probing pulse (Figure 3).

According to the arrival time of the force pulse, the propagation velocity of the $\mathrm{SH}$ wave was estimated on the formula:

$$
C=\frac{L}{t_{R P}-t_{P P}},
$$

where $L$ is the distance passed by the wave, $t_{R P}$ and $t_{P P}$ are the time recorded in the receiving and probing pulses respectively (as a rule, in the zero crossing).

It was assumed that the distance traveled by the wave was $300 \mathrm{~mm}$.

\section{EXPERIMENTAL SETUP}

In experimental studies, an aluminum balloon with an external diameter of $300 \mathrm{~mm}$ was used. Two types of measurements were produced on the balloon: wall thickness and wave propagation velocity. Schemes of experimental setups are shown in Figure 7.

The technique for measuring the wall thickness was as follows. The balloon surface was uniformly marked (Figure 8) with step in the axial direction of $50.5 \mathrm{~mm}$ and step in the azimuth direction of $12^{\circ} 15^{\prime}$, corresponding to $58.9 \mathrm{~mm}$. Thus, in the axial direction 13 points are marked, in the azimuth -16 , in total -208 points. At each point, a measurement was made at a frequency of $5 \mathrm{MHz}$ using a high-frequency DIO-1000PA and a contact fluid. On the received signals (Figure $9 a$ ), to increase the accuracy of the measurements, the fourth reflection from the balloon walls was evaluated. The sampling frequency was $205 \mathrm{MHz}$.

The method for measuring the velocity of wave propagation included the following steps. Marking on the surface of an aluminum cylinder in the form of a circle with a graduated scale every degree. Excitation and reception of SH waves using specialized transducers with dry point contact at a frequency of $105 \mathrm{kHz}$ using a low-frequency DIO-1000LF. Measurement of 
the propagation time of the wave according to the received signals and the translation of the time value into the velocity according to the formula (3). The distance traveled by the wave was $303 \mathrm{~mm}$. To increase the accuracy of calculating the wave propagation velocity, the sampling frequency of the signal increased to $41 \mathrm{MHz}$, only the received signal of a horizontally polarized shear wave was recorded (Figure $9 b$ ).

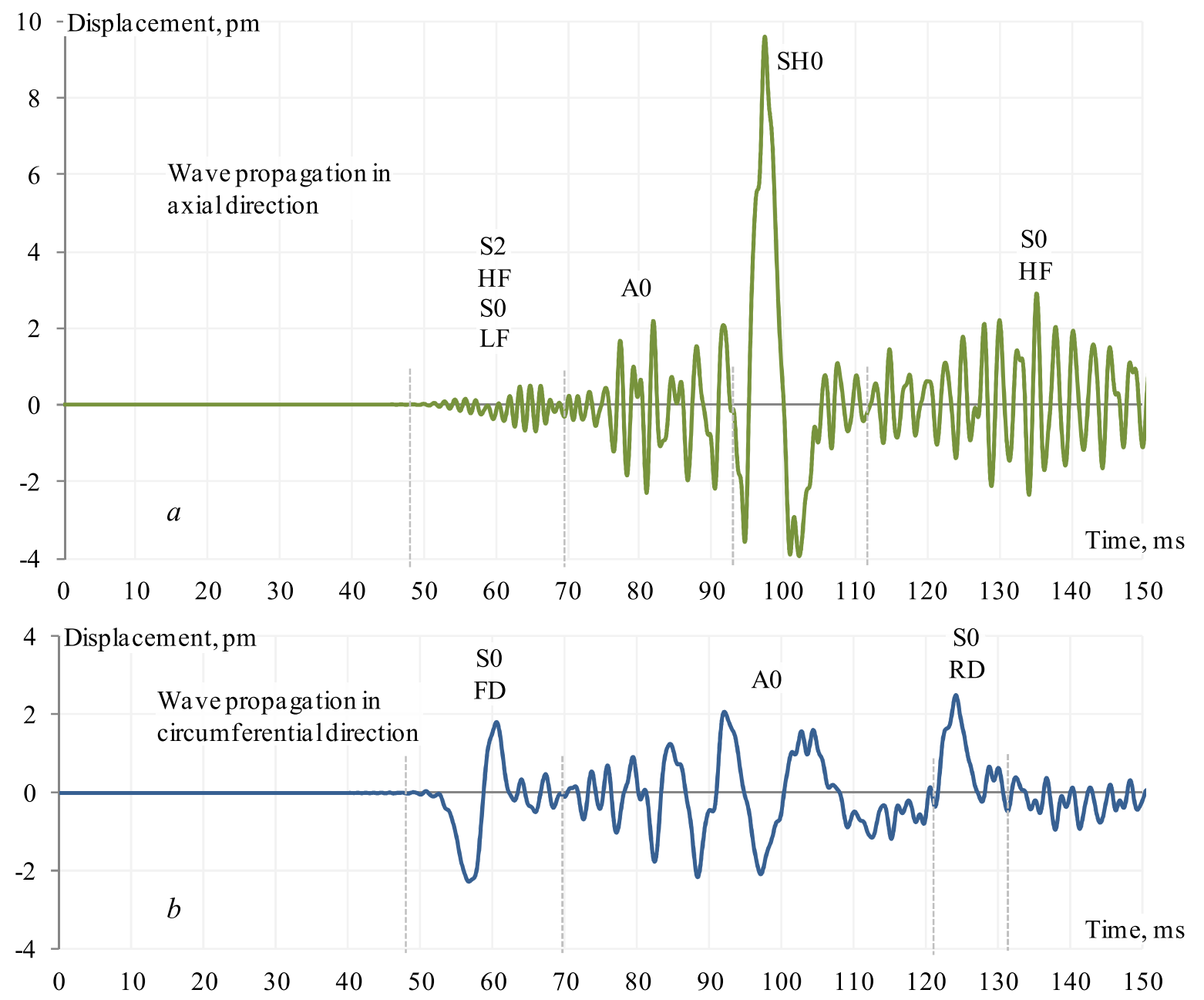

Figure 6. Signals obtained at various points on the outer surface (where $a-$ in axial direction, $b-$ in circumferential direction (Figure 5)) of a hollow cylinder: LF - low frequency (less than $200 \mathrm{kHz}$ ), $\mathrm{HF}$ - high frequency (more than $400 \mathrm{kHz}$ ), FD - forward direction, $\mathrm{RD}$ - reverse (opposite) direction from point of application of tangential force (Figure $2 a$ )

Both in measuring the wall thickness of the balloon and in measuring the wave propagation velocity, the propagation time of the wave was estimated from the transition from the positive to the negative phase of the elastic oscillations.

\section{RESULTS AND DISCUSSION}

Figure 10 shows the results of measuring the wall thickness of an aluminum balloon. On the distribution the wall thickness is observed, and on the right side (values in the azimuth component from 150 to 300 degrees) it has higher values compared to the left part (values for the azimuth component from 0 to 120 degrees). There is also a local minimum in the region of 
Myshkin Yu. V., Murav'eva O. V., Sannikova Yu. O., Chukhlanceva T. S.

"The propagation of horizontally polarized shear wave in the hollow cylinder"

20 degrees in the fourth quadrant, corresponding to a wall thickness of $5.39 \mathrm{~mm}$. Thus, in one direction along the azimuth from the origin, the wall thickness increases ( 1 and 2 quadrants) from 5.47 to $5.75 \mathrm{~mm}$, on the other side ( 3 and 4 quadrants), first decreases, then increases and lies in the range from 5.42 to $5.63 \mathrm{~mm}$. The average value of the wall thickness from the results of all measurements was $5.61 \mathrm{~mm}$.

This unevenness in the wall thickness can be explained by the technological treatment of the balloon surface during its manufacture. In turn, such processing could lead to inhomogeneity in the structure of the material.

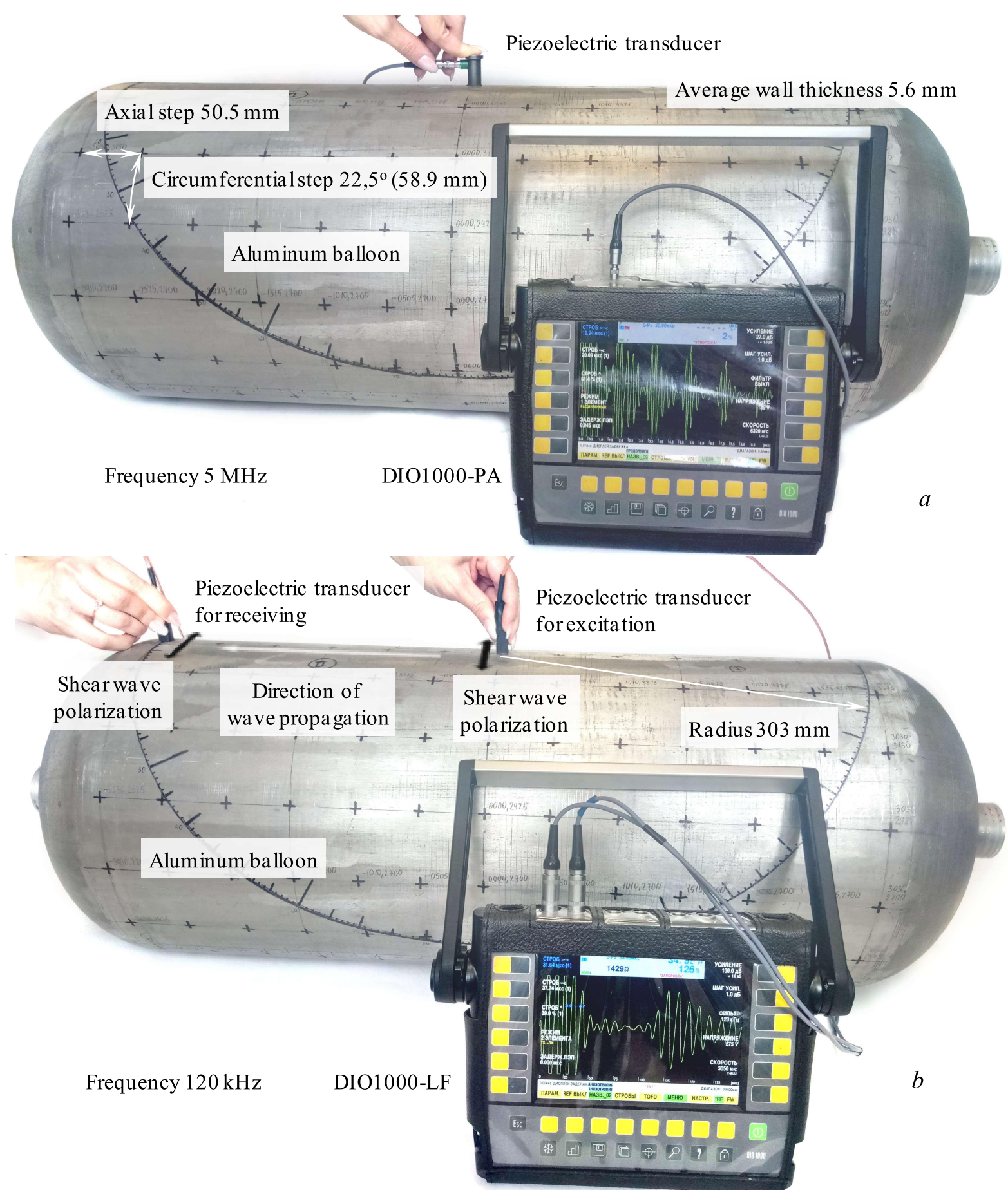

Figure 7. The experimental setup: for measuring the wall thickness $(a)$; for measuring the propagation velocity of the horizontally polarized shear wave $(b)$ 


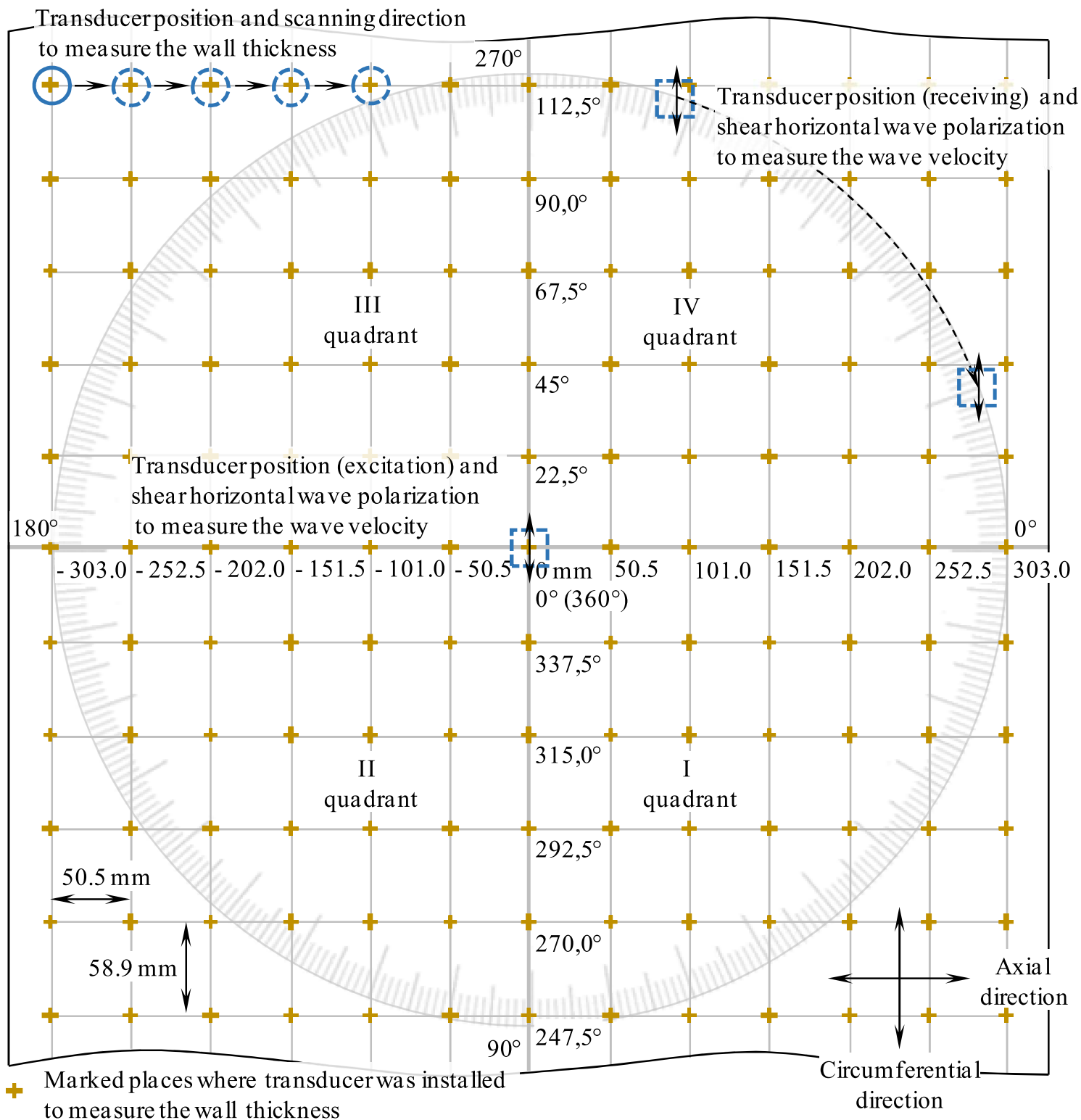

Figure 8. The scanning scheme for determining wall thickness and propagation velocity of the horizontally polarized shear wave

Figure 11 shows the dependence of the propagation velocity of a horizontally polarized shear wave on the wave propagation direction. Simulation showed that in circumferential direction of the hollow cylinder wave velocity is higher, which is explained by the smaller distance traveled by the wave. Since the curved surface of the hollow cylinder has an inner and outer diameter, the wave overcomes a relatively smaller distance along the inner surface, which is expressed in an increase in the propagation velocity (which, as such, does not occur). In this case, the shape of the pulse is distorted and the further the wave propagates, the stronger this distortion (for example, the longitudinal wave pulse in Figure $6 \mathrm{~b}$ in the opposite direction does not have the same form as in the forward direction). The velocity of the horizontally polarized shear wave in the axial direction was $3133 \mathrm{~m} / \mathrm{s}$, which can be assumed not to be distorted by the curvature of the surface of the hollow cylinder. The velocity in the circumferential direction was $3220 \mathrm{~m} / \mathrm{s}$, the minimum value of $3115 \mathrm{~m} / \mathrm{s}$ is observed at angles of $10-15$ degrees in each quadrant. The average velocity value from the results of all measurements 
was $3181 \mathrm{~m} / \mathrm{s}$. Thus, the range of velocity variation based on simulation results was $95 \mathrm{~m} / \mathrm{s}$ (from $3115 \mathrm{~m} / \mathrm{s}$ to $3220 \mathrm{~m} / \mathrm{s}$ ).

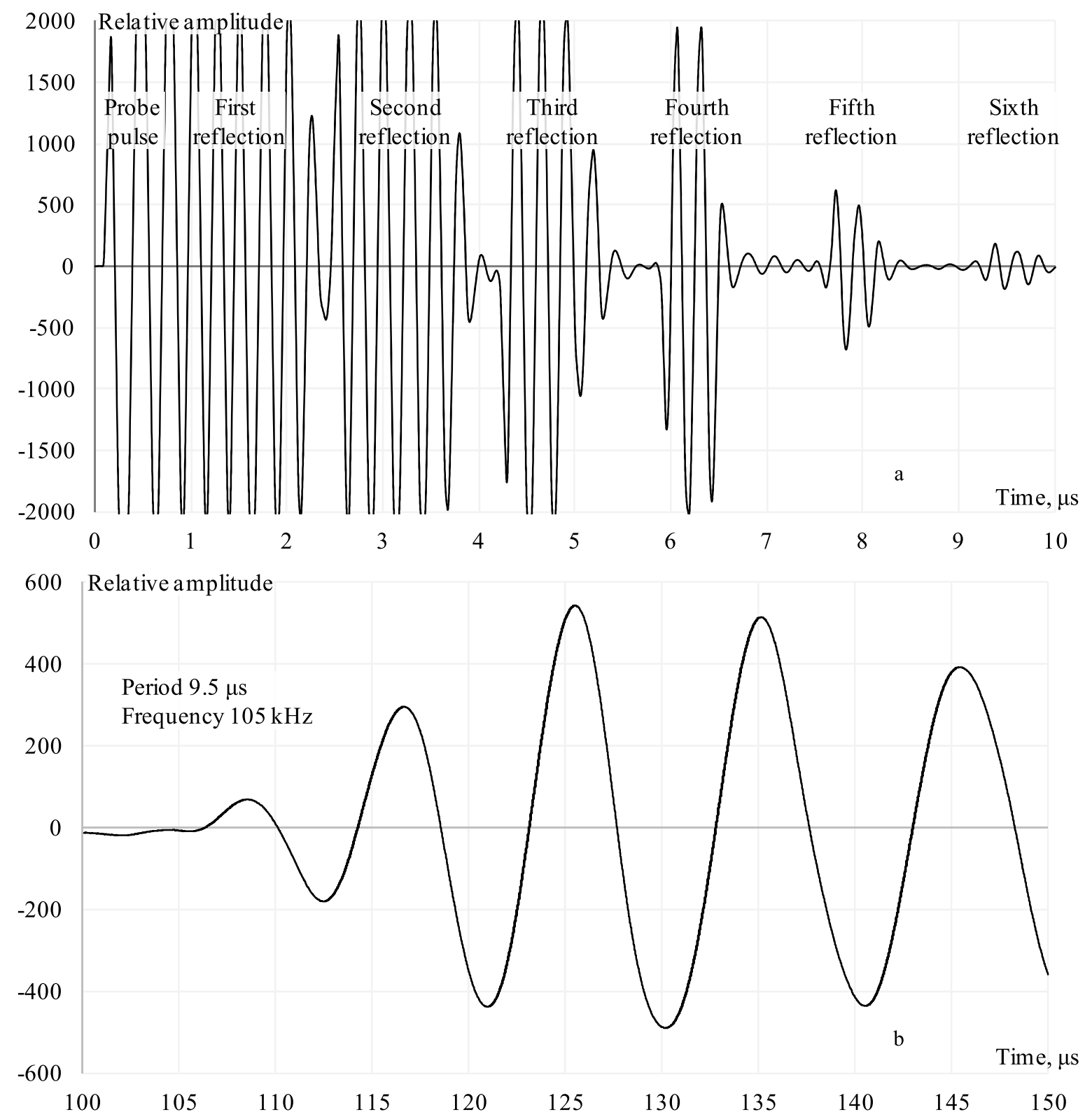

Figure 9. Signals obtained at one of the points on the outer surface of a hollow cylinder when measuring its wall thickness $(a)$ and when measuring the propagation velocity of the horizontally polarized shear wave $(b)$

When evaluating the experimental results, a similar dependence is observed with the simulation results in terms of increasing the propagation velocity in circumferential direction of the hollow cylinder. Thus, the maximum velocity is observed in the circumferential direction and is $3306 \mathrm{~m} / \mathrm{s}$. A minimum velocity of $3109 \mathrm{~m} / \mathrm{s}$ is observed in the direction of the minimum wall thickness of the aluminum balloon, with the minimum velocity range lying in the range of 325 to 350 degrees in the fourth quadrant. The decrease in the velocity of wave propagation is partly explained by the same principle as the change in velocity in the circumferential direction: the wave travels a greater distance, since the radius of curvature of the inner 
surface of the hollow cylinder increases. However, it must be taken into account that when manufacturing a cylinder as a result of technological operations, changes in the structure of the material may have occurred, which affected the elastic properties. The average velocity for all calculations was $3191 \mathrm{~m} / \mathrm{s}$. In this case, the range of variation based on the results of experimental measurements was $197 \mathrm{~m} / \mathrm{s}$ (from $3109 \mathrm{~m} / \mathrm{s}$ to $3306 \mathrm{~m} / \mathrm{s}$ ).

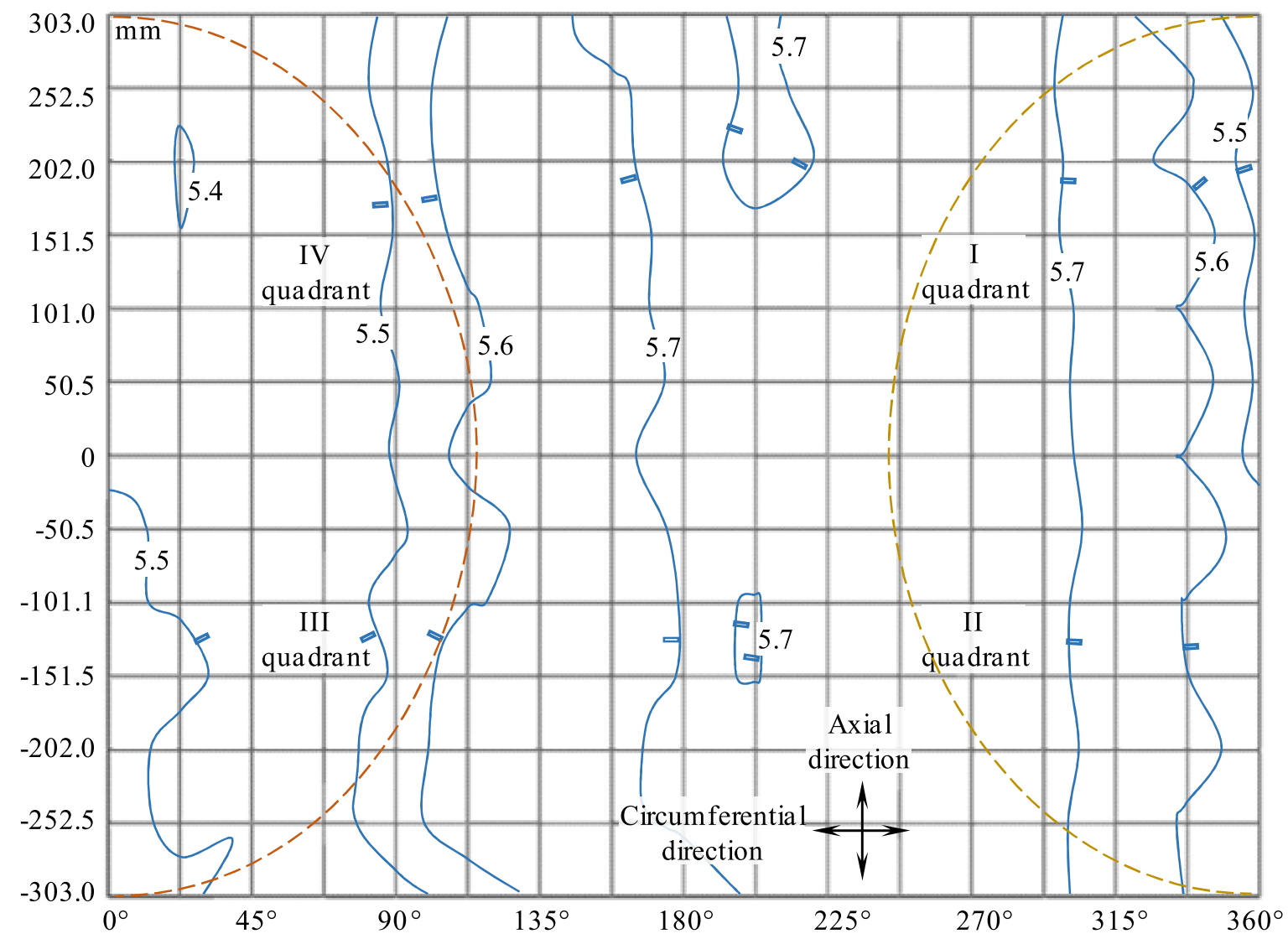

Figure 10. Results of thickness measurement: the markup corresponds to the Figure 8, solid lines indicate the lines of the contour with the same value of the wall thickness

\section{CONCLUSIONS}

According to the results of studies of the propagation of a horizontally polarized shear wave in a hollow aluminum cylinder, the following conclusions can be drawn.

The propagation velocity of the $\mathrm{SH}$ wave depends on the direction: in the axial direction, the velocity is less than in the circumferential direction of the hollow cylinder. In the investigated aluminum cylindrical object with an external diameter of $300 \mathrm{~mm}$ and a wall thickness of $5.675 \mathrm{~mm}$, the difference of velocity was $95 \mathrm{~m} / \mathrm{s}$.

Experimental studies also showed an increase in the SH wave velocity in the circumferential direction of a hollow cylinder, regardless of the wall thickness. As the wall thickness increases, the velocity increases: the wave travels a smaller distance along the inner surface of the hollow cylinder.

The results of the research can be used to develop methods for guided wave testing of large-sized cylindrical objects or large-diameter pipelines, when calculating the focusing laws at an angle to the axial direction of the hollow cylinder. 
Myshkin Yu. V., Murav'eva O. V., Sannikova Yu. O., Chukhlanceva T. S.

"The propagation of horizontally polarized shear wave in the hollow cylinder"

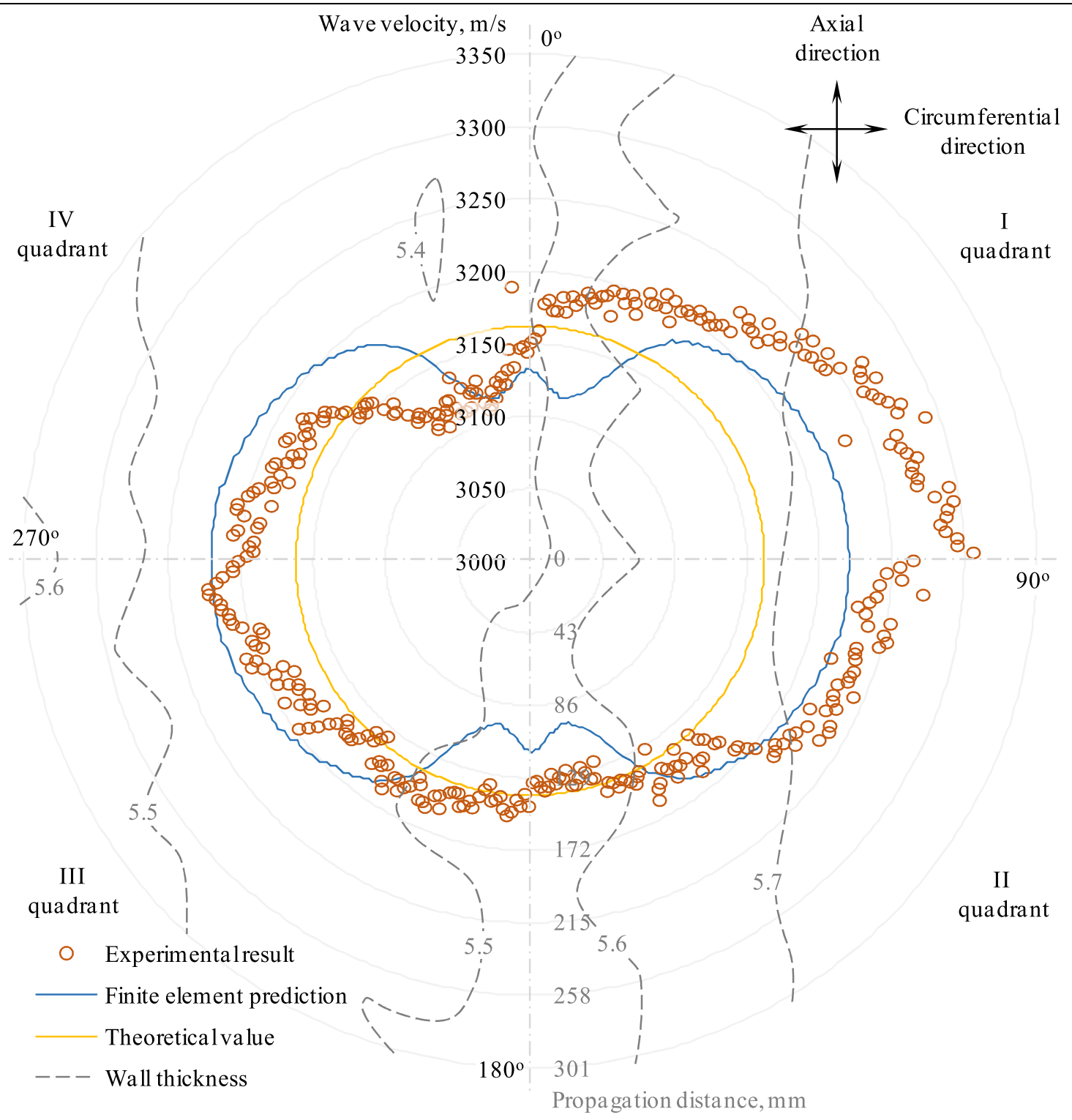

Figure 11. Dependence of horizontally polarized shear wave on direction of the propagation in the hollow aluminum cylinder: upper scale (wave velocity) refers to experimental result, finite element prediction and theoretical value; lower scale (propagation distance) refers to wall thickness

This work was supported by the Russian Science Foundation (Project No. 18-79-10122).

\section{REFERENCES}

1. Zlobin, D. V., \& Muravieva, O. V. (2012). Development features of electromagnetic acoustic defectoscopy equipment for bar iron using rod waves. Bulletin of Kalashnikov ISTU, (4), 99-104. Retrieved from http://izdat.istu.ru/index.php/vestnik/article/download/2682/1450 (in Russian).

2. Strizhak, V. A., Hasanov, R. R., \& Pryakhin, A. V. (2018). Features of excitation of an electromagnetic acoustic transducer under a waveguide method of testing. Bulletin of Kalashnikov ISTU, 21(2), 159-166. doi: 10.22213/2413-1172-2018-2-159-166 (in Russian).

3. Muravyova, O. V., \& Murashov, S. A. (2011). Use of torsional waves for detection of operational defects in pump rods and tubing. Bulletin of Kalashnikov ISTU, (2), 149-154. Retrieved from http://izdat.istu.ru/ index.php/vestnik/article/download/2279/1047 (in Russian). 
"Instrumentation Engineering, Electronics and Telecommunications - 2018"

Proceedings of the IV International Forum (Izhevsk, Russia, December, 12-14, 2018)

4. Muravyov, V. V., Baiteriakov, A. V., \& Kotolomov, A. Y. (2014). Influence of structural state of metal of gas pipelines on parameters of ultrasonic waves. Bulletin of Kalashnikov ISTU, (3), 125-128. Retrieved from http://izdat.istu.ru/index.php/vestnik/article/download/2985/1753 (in Russian).

5. Muravyov, V. V., Balobanov, E. N., \& Pechina, E. A. (2013). Determination of elastic acoustic coupling coefficients of ferromagnetic metals. Bulletin of Kalashnikov ISTU, (2), 108-112. Retrieved from http://izdat.istu.ru/index.php/vestnik/article/download/2215/983 (in Russian).

6. Murav'ev, V. V., Volkova, L. V., Platunov, A. V., Buldakova, I. V., \& Gushchina, L. V. (2018). Investigations of the structural and strain-stress state of the rails of current production by the acoustic elasticity method. Bulletin of Kalashnikov ISTU, 21(2), 13-23. doi: 10.22213/2413-1172-2018-2-13-23 (in Russian).

7. Murav'eva, O. V., \& Sokov, M. Y. (2016). Influence of the defect depth on the parameters of electromagnetic-acoustic multiple-shadow method of the rod testing. Bulletin of Kalashnikov ISTU, 19(3), 46-50. doi: 10.22213/2413-1172-2016-3-46-50 (in Russian).

8. Petrov, K. V., Sokov, M. Y., \& Muraveva, O. V. (2018). The effect of electromagnetic acoustic transducer design features on results of cylinder object testing. Bulletin of Kalashnikov ISTU, 21(2), 135-146. doi: 10.22213/2413-1172-2018-2-135-146 (in Russian).

9. Clough, M., Fleming, M., \& Dixon, S. (2017). Circumferential guided wave EMAT system for pipeline screening using shear horizontal ultrasound. NDT \& E International, 86, 20-27. doi: 10.1016/j.ndteint. 2016.11.010.

10. Deng, M., Gao, G., Xiang, Y., \& Li, M. (2017). Assessment of accumulated damage in circular tubes using nonlinear circumferential guided wave approach: A feasibility study. Ultrasonics, 75, 209-215. doi: 10.1016/j.ultras.2016.12.001.

11. Li, M., Deng, M., Gao, G., \& Xiang, Y. (2018). Modeling of second-harmonic generation of circumferential guided wave propagation in a composite circular tube. Journal of Sound and Vibration, 421, 234-245. doi: 10.1016/j.jsv.2018.01.060.

12. Howard, R., \& Cegla, F. (2017). On the probability of detecting wall thinning defects with dispersive circumferential guided waves. NDT \& E International, 86, 73-82. doi: 10.1016/j.ndteint.2016.11.011.

13. Heinlein, S., Cawley, P., \& Vogt, T. K. (2018). Reflection of torsional T(0,1) guided waves from defects in pipe bends. NDT \& E International, 93, 57-63. doi: 10.1016/j.ndteint.2017.09.007.

14. Khalili, P., \& Cawley, P. (2018). Relative ability of wedge-coupled piezoelectric and meander coil EMAT probes to generate single-mode Lamb waves. IEEE transactions on ultrasonics, ferroelectrics, and frequency control, 65(4), 648-656. doi: 10.1109/TUFFC.2018.2800296.

15. Dobson, J., \& Cawley, P. (2017). The scattering of torsional guided waves from Gaussian rough surfaces in pipework. The Journal of the Acoustical Society of America, 141(3), 1852-1861. doi: 10.1121/1.4978244.

16. Alleyne, D., Jones, R., \& Vogt, T. (2017). An introduction to long-range screening using guided waves. $M a-$ terials Evaluation, 75(10), 1206-1213.

17. Khalili, P., \& Cawley, P. (2018). The choice of ultrasonic inspection method for the detection of corrosion at inaccessible locations. NDT \& E International, 99, 80-92. doi: 10.1016/j.ndteint.2018.06.003.

18. Myshkin, Y. V., \& Muravieva, O. V. (2017). The features of the guided wave excitation and propagation at testing of pipes. Journal of Physics: Conference Series, 881(1), 012019. doi: 10.1088/17426596/881/1/012019.

19. Muravev, V. V., Muraveva, O. V., Strizhak, V. A., \& Myshkin, Y. V. (2017). Acoustic guided wave testing of pipes of small diameters. IOP Conference Series: Materials Science and Engineering, 253(1), 012001. doi: $10.1088 / 1757-899 X / 253 / 1 / 012001$.

20. Muravieva, O. V., Strizhak, V. A., Zlobin, D. V., Murashov, S. A., Pryakhin, A. V., \& Myshkin, Y. V. (2016). Acoustic guided wave testing of downhole pumping equipment elements. Oil Industry Journal, (09), 110-115. Retrieved from https://www.onepetro.org/journal-paper/OIJ-2016-09-110-115-RU (in Russian).

21. Murav'eva, O. V., Len'kov, S. V., \& Murashov, S. A. (2016). Torsional waves excited by electromagneticacoustic transducers during guided-wave acoustic inspection of pipelines. Acoustical Physics, 62(1), 117-124. doi: 10.1134/S1063771015060093.

22. Budenkov, G. A., Nedzvetskaya, O. V., Zlobin, D. V., \& Lebedeva, T. N. (2004). The application efficiency of rod and torsional waves for checking rod-shaped roll stock. Russian Journal of Nondestructive Testing, 40(3), 147-151. doi: 10.1023/B:RUNT.0000040171.56679.6b. 
Myshkin Yu. V., Murav’eva O. V., Sannikova Yu. O., Chukhlanceva T. S.

"The propagation of horizontally polarized shear wave in the hollow cylinder"

23. Budenkov, G. A., Nedzvetskaya, O. V., Zlobin, D. V., \& Murashov, S. A. (2006). Interaction of torsion waves with longitudinal cracks in tubes. Russian Journal of Nondestructive Testing, 42(6), 392-397. doi: 10.1134/S1061830906060064.

24. Kudela, P., Radzienski, M., Ostachowicz, W., \& Yang, Z. (2018). Structural health monitoring system based on a concept of Lamb wave focusing by the piezoelectric array. Mechanical Systems and Signal Processing, 108, 21-32. doi: 10.1016/j.ymssp.2018.02.008.

25. Muller, A., Robertson-Welsh, B., Gaydecki, P., Gresil, M., \& Soutis, C. (2017). Structural health monitoring using Lamb wave reflections and total focusing method for image reconstruction. Applied Composite Materials, 24(2), 553-573. doi: 10.1007/s10443-016-9549-5.

26. Brath, A. J., Simonetti, F., Nagy, P. B., \& Instanes, G. (2017). Guided wave tomography of pipe bends. IEEE transactions on ultrasonics, ferroelectrics, and frequency control, 64(5), 847-858. doi: 10.1109/TUFFC. 2017.2683259.

27. Taheri, H., Du, J., \& Delfanian, F. (2017). Experimental observation of phased array guided wave application in composite materials. Materials Evaluation, 75(10), 1308-1316.

28. Rose, J. L. (2014). Ultrasonic guided waves in solid media. Cambridge, USA : Cambridge University Press. doi: 10.1017/CBO9781107273610.

29. Yu, L., \& Tian, Z. (2016). Guided wave phased array beamforming and imaging in composite plates. Ultrasonics, 68, 43-53. doi: 10.1016/j.ultras.2016.02.001.

30. Wang, W., Zhang, H., Lynch, J. P., Cesnik, C. E., \& Li, H. (2018). Experimental and numerical validation of guided wave phased arrays integrated within standard data acquisition systems for structural health monitoring. Structural Control and Health Monitoring, 25(6), e2171. doi: 10.1002/stc.2171.

31. Vinogradov, S., Cobb, A., Bartlett, J., \& Udagawa, Y. (2018). Development of a novel omnidirectional magnetostrictive transducer for plate applications. AIP Conference Proceedings, 1949(1), 090002. doi: 10.1063/1.5031565.

32. Sun, Z., Sun, A., \& Ju, B. F. (2018). Guided wave imaging of oblique reflecting interfaces in pipes using common-source synthetic focusing. Journal of Sound and Vibration, 420, 1-20. doi: 10.1016/j.jsv.2018. 01.012 .

33. Gaul, T., Schubert, L., Weihnacht, B., \& Frankenstein, B. (2014, July). Localization of defects in pipes using guided waves and synthetic aperture focussing technique (SAFT). In: V. Le Cam, L. Mevel, F. Schoefs (Eds.), EWSHM - 7th European Workshop on Structural Health Monitoring (pp. 520-527). Nantes, France : IFFSTTAR, Inria, Université de Nantes. Retrieved from https://hal.inria.fr/hal-01020390.

34. Davies, J., \& Cawley, P. (2009). The application of synthetic focusing for imaging crack-like defects in pipelines using guided waves. IEEE Transactions on Ultrasonics, Ferroelectrics, and Frequency Control, 56(4). 759-771. doi: 10.1109/TUFFC.2009.1098.

35. Davies, J., Simonetti, F., Lowe, M., \& Cawley, P. (2006). Review of synthetically focused guided wave imaging techniques with application to defect sizing. AIP Conference Proceedings, 820(1), 142-149. doi: 10.1063/1.2184522.

36. Davies, J., \& Cawley, P. (2007). The application of synthetically focused imaging techniques for high resolution guided wave pipe inspection. AIP Conference Proceedings, 894(1), 681-688. doi: 10.1063/1.2718036.

37. Liu, Z., Sun, K., Song, G., He, C., \& Wu, B. (2016). Damage localization in aluminum plate with compact rectangular phased piezoelectric transducer array. Mechanical Systems and Signal Processing, 70-71, 625-636. doi: 10.1016/j.ymssp.2015.09.022.

38. Zhang, J., Drinkwater, B. W., \& Wilcox, P. D. (2012). Effect of roughness on imaging and sizing rough crack-like defects using ultrasonic arrays. IEEE Transactions on Ultrasonics, Ferroelectrics, and Frequency Control, 59(5), 939-948. doi: 10.1109/TUFFC.2012.2278.

39. Petcher, P. A., \& Dixon, S. (2015). Weld defect detection using PPM EMAT generated shear horizontal ultrasound. NDT \& E International, 74, 58-65. doi: 10.1016/j.ndteint.2015.05.005.

40. Fletcher, S., Lowe, M. J., Ratassepp, M., \& Brett, C. (2012). Detection of axial cracks in pipes using focused guided waves. Journal of Nondestructive Evaluation, 31(1), 56-64. doi: 10.1007/s10921-011-0120-x. 